\title{
TIRANIAS DA IDENTIDADE DO PROFESSOR DE LE: CRENÇAS, EMOÇÕES E AÇÕES POR MEIO DA LINGUAGEM
}

\author{
Helvio Frank de Oliveira ${ }^{1}$
}

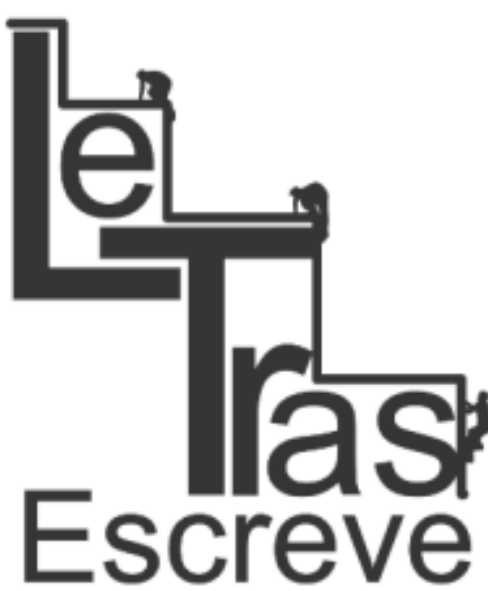

(ISSN 2238-8060)
RESUMO: A partir de estudos situados e relacionados a contextos escolares e universitários, de ensino-aprendizagem e de formação inicial e continuada docente, neste texto busco discutir a problemática social da identidade do professor de línguas estrangeiras, vislumbrando possíveis aspectos dimensionadores dessa relação. Para isso, ancoro-me em autores da Linguística Aplicada Crítica e da Pedagogia Crítica para compreender como o trabalho social docente com a linguagem pode ser produtivo na des/re/construção de crenças, representações, emoções e de práticas discursivas contextualizadas, com vistas a repercutir (in)diretamente na própria identidade e na do/s outro/s. Considerando as tiranias da identidade do professor de línguas e, ao mesmo tempo, apontando possibilidades linguísticas de se fortalecer o status social da docência e o ensino da língua estrangeira, vasculho historicamente o conceito de identidade, rastreando seu percurso interdisciplinar no que tange aos aspectos social, cultural, cognitivo e discursivo em simbiose com outros conceitos clássicos provenientes da Linguística Aplicada. Como exemplos para problematização, utilizo fragmentos de histórias de vida tratadas sob o fazer narrativo e analiso-as à luz das condições de produção e circulação que (d)enunciam a ação docente por meio da própria linguagem e identidade incorporadas a outros elementos delas constituidores: crenças, emoções, representações etc. Finalizo com a apresentação de pontos profícuos sobre como o professor de línguas estrangeiras pode fazer do objeto linguagem a sua ponte entre ensino de conteúdo, cultura, vida e mudança social. PALAVRAS-CHAVE: Docência. Identidade/s. Linguagem.

\section{TYRANNIES OF THE FOREIGN LANGUAGE PROFESSOR'S IDENTITY: BELIEFS, EMOTIONS, AND ACTIONS THROUGH LANGUAGE}

ABSTRACT: Based on contextualized studies and related to school and university settings, teaching and learning and pre-service and in service teacher education, in this paper we discuss the social problems of the foreign language teacher's identity, observing possible aspects that extend this dimension. For this, we support the authors in Critical Applied Linguistics and Critical Pedagogy to understand how teaching social work with the language can be productive to de/re/construction of beliefs, representations, emotions and contextualized discursive practices, in order to reverberate (in)directly on own teacher's identity. Considering social aspects of the language teacher's identity and at the same time pointing out linguistic possibilities of strengthening the social status of foreign language teaching, we historically argue about the concept of identity, indicating its interdisciplinary course with regard to social, cultural, cognitive and discursive charac-

\footnotetext{
${ }^{1}$ Professor efetivo da Universidade Estadual de Goiás, com atuação permanente nos Programas de Pós-Graduação Stricto Sensu: Interdisciplinar em Educação, Linguagem e Tecnologias (PPGIELT) e em Língua, Literatura e Interculturalidade (POSLLI). É doutor em Linguística pela Universidade Federal de Goiás, com realização de estágio pós-doutoral em Linguística Aplicada na Universidade de Brasília. Email: helviofrank@hotmail.com
}

https://periodicos.unifap.br/index.php/letras

Macapá, v. 6, n. 2, 2o semestre, 2016. 
teristics together with other classic constructs from Applied Linguistics. As examples for questioning, we presented fragments of narrative life histories and analyze them in the light of the conditions of production and circulation that enunciate teaching work through own language and identity incorporated into other elements which constitute them: beliefs, emotions, representations etc. We conclude with the presentation of relevant points about how foreign language teachers can make difference when they teach language and consequently educational content, culture, life and social change. KEYWORDS: Teaching. Identities. Language.

\section{Crenças e experiências no contexto de ensino/aprendizagem de línguas}

As crenças, levando-se em consideração a abordagem contextual para sua investigação (BARCELOS, 2001), são fenômenos variáveis e influenciados pelo contexto (pessoas, sistema organizacional etc.), construídos socialmente por meio da interação e da

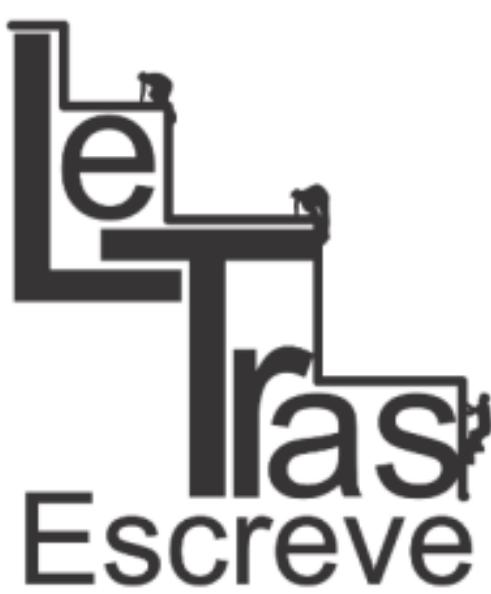

(ISSN 2238-8060) negociação de significados sociais, diretamente imbricados com as experiências de indivíduos em sociedade, formando, conforme Dewey (1938), a base da Educação. Para Barcelos (2004, p. 40), crenças são conhecimentos intuitivo implícito e/ou explícito de indivíduos baseados na experiência. $O$ termo representa uma firme convicção, opinião e/ou ideia que tem o indivíduo com relação a algo. Essa convicção está ligada a instituições que têm como base as experiências pessoais vivenciadas (problemas, sentimentos, impressões e da interação com o ambiente), o tipo de personalidade e a influência de terceiros, pois elas são construídas socialmente e repercutem nas suas intenções, ações, comportamento, atitude, motivações e expectativas para atingir determinado objetivo. Nesse caminho, é possível perceber que crenças estejam imbricadas nas relações provenientes (ou não) das experiências humanas e, por essa razão, faz-se necessário investigá-las, conforme preconizam estudos desenvolvidos na área (BARCELOS, 2001; OLIVEIRA, 2013).

As crenças são processos construídos, cultural e socialmente, a partir das experiências pessoais vivenciadas pelo indivíduo e de sua reflexão acerca do conhecimento adquirido por intermédio dessa convivência. Compreender a natureza das crenças denota 


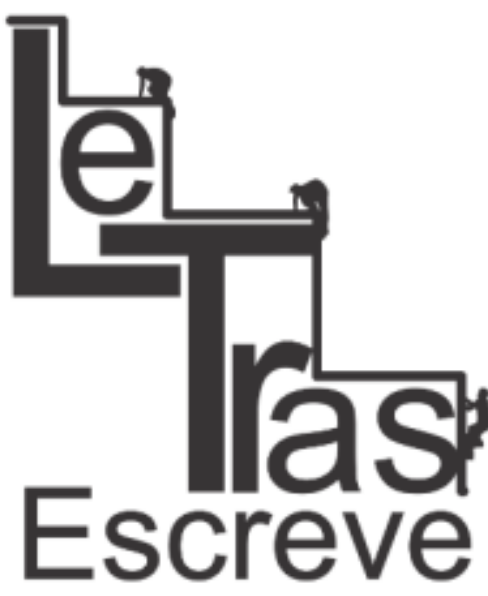

(ISSN 2238-8060)

analisar o contexto em que elas estão inseridas, e estudá-las traz como relevância ao indivíduo o autoconhecimento e a adaptação no processo de lidar com valores compartilhados.

As crenças podem dialogar tanto com os preceitos da teoria sociocultural (VYGOTSKY, 1998, 2001) quanto com os balizamentos teóricos da dialogia bakhtiniana (BAKHTIN, 1992), uma vez que, no contexto de sala de aula e até mesmo em outros espaços sociais em que construímos conhecimentos, há um contexto de negociação de significados via linguagem, por meio do qual cada um desses sujeitos em interação se constitui e constrói sua aprendizagem com base na experiência de/com o outro.

Do ponto de vista sociocultural, as crenças movimentamse e modificam-se conforme as práticas sociais e discursivas vão sendo reconstruídas por meio das experiências e vivências culturais de determinado/s indivíduo/s e/ou grupo/s inserido/s em diversos contextos. Nas palavras de Barcelos (2006), as crenças também são sociais porque nascem de experiências e problemas, de nossa interação com o contexto e da nossa capacidade de refletir e pensar sobre o que nos cerca. Já do ponto de vista bakhtiniano, as crenças podem ser polifônicas e dialógicas, tendo em vista que refletem uma visão pessoal sobre o objeto em questão e ecoam aspectos presentes nos discursos prevalecentes na sociedade.

A compreensão das crenças é essencial para melhorar a prática de professores e a preparação de programas de ensino. Como ressalta Barcelos (2004), o processo de reflexão a que os professores são submetidos pode torná-los mais conscientes de suas crenças e das inconsistências de suas práticas. Portanto, estudá-las reside no fato de que elas podem exercer grande influência no processo. Positivas ou negativas, as crenças podem ajudar ou prejudicar as construções sociais e culturais dos indivíduos em interação (BARCELOS, 2006).

Como vimos, as crenças estão inter-relacionadas com as experiências e se desenvolvem à medida que o indivíduo interage e modifica (e é modificado por) suas experiências. Assim, as crenças 


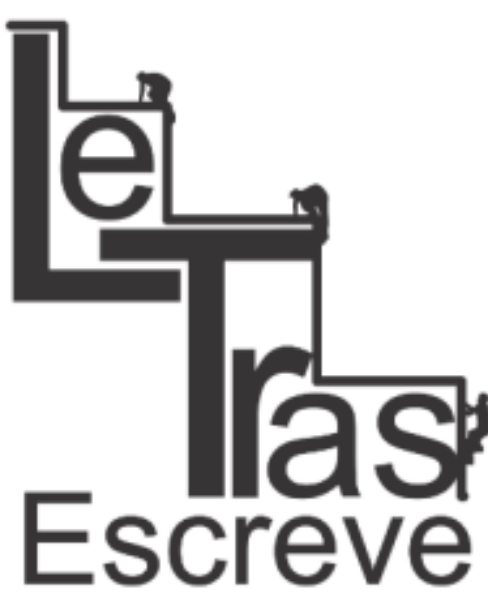

(ISSN 2238-8060) incorporam-se às perspectivas sociais, pois nascem no contexto da interação e na relação com os grupos sociais. Além disso, a autora assinala que as experiências pessoais dos indivíduos contribuem para moldar suas crenças e suas ações no contexto social, sendo (re)construídas (e formadas) o tempo todo, à medida que o indivíduo se depara com novas situações e informações.

Em se tratando de experiências, como avalia Miccoli (2007) os eventos sobre aprender consolidam-se por meio de interações entre uma infinitude de processos e subsistemas: biológico, cognitivo, cultural (incluindo os artefatos culturais), sócio histórico, e todos os fatores que esses aspectos implicam, por se tratar de um sistema complexo. Somado a essa ideia, há que se lembrar também da correlação existente entre um determinado contexto e um ser humano que pensa, sente e atua de forma única numa situação típica de construção social.

Dewey (1938) afirma que o processo educacional consiste em ações contínuas de reconstrução de experiências, já que estas se caracterizam pela interação e adaptação a partir do princípio de continuidade dos envolvidos em seus contextos. Esse princípio de continuidade pode se efetivar na medida em que há interação e adaptação do indivíduo ao contexto, provocando grandes embates ao interpor, nessa atuação, valores de experiências anteriores para a modificação das experiências futuras.

O autor compreende que conceitos de situação e interação são inseparáveis dentro do princípio de continuidade das experiências, tendo em vista que, ao viver uma situação, o indivíduo vive mais que uma, pois implica estar vivenciando uma série de interações entre ele próprio, os objetos e outros indivíduos. Além disso, o ambiente, tido como "as condições em interação com necessidades pessoais, desejos, propósitos e capacidades para criar a experiência que se tem"2 (DEWEY, 1938, p. 6), é um elemento muito importante, por desencadear acontecimentos em situação especifica.

\footnotetext{
2 "[...] whatever conditions interact with personal needs, desires purposes and capacities to create the experience which is had". (DEWEY, 1938, p. 6).
} 


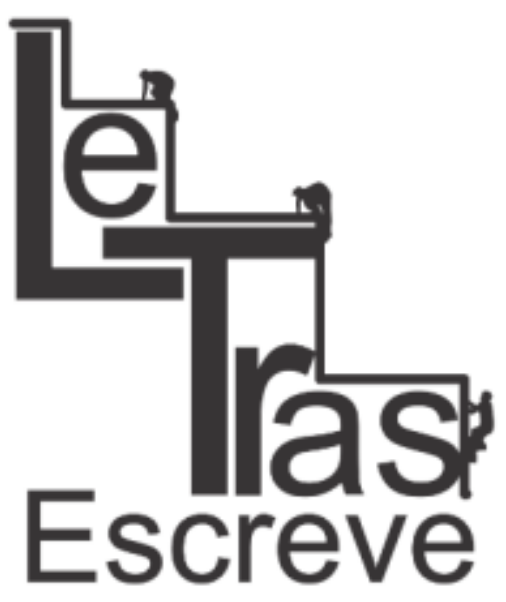

(ISSN 2238-8060)

Recorrendo às bases filosóficas, Dewey (1938) descarta a experiência como fenômeno meramente cognitivo e confirma sua natureza biológica dos seres vivos em seus meios físicos e sociais. Para o autor, não haveria como se entender experiência como fenômeno puramente cognitivo, e ela inclui o que é experienciado, quem experiencia e o modo como se experiencia. Portanto, trata a experiência como conceito orgânico, o qual não pode se separar do meio físico e social.

À proposta deweyana, é preciso elencar o princípio de continuidade $^{3}$ ou da experiência contínua para discussão. Nessa expectativa, a concepção de ser vivo é natural, relacionada com o meio em que vive, evolui e se desenvolve, por meio de pensamentos, percepções, sentimentos, sofrimentos e ações em um processo interativo, contínuo e transformador do meio e dos seres humanos que nele vivem. Afinal, a estreita relação entre agir, sofrer ou vivenciar forma a experiência.

\section{Identidade/s e contexto de ensino/aprendizagem de línguas}

Dentro da área de Linguística Aplicada, Barcelos (2013) advoga sobre a relação entre identidade/s e crenças na construção de conhecimentos e valores humanos, especialmente no contexto de ensino e aprendizagem de línguas. A partir de estudos interdisciplinares, é possível observar que o conceito "representações", utilizado pelo sociólogo Hall (2009), é bastante similar ao de "crenças" em suas caracterizações, uma vez que as representações são processos culturais e simbólicos, baseados em valores, posições e lugares construídos socialmente. $\mathrm{O}$ autor avalia que, para analisar a cultura, significado e identidades, é necessário o exame dos sistemas de

\footnotetext{
${ }^{3}$ Princípio biológico pelo qual pressupõe que toda nova experiência é construída a partir das experiências anteriores do indivíduo. Assim, cada experiência realizada e vivenciada modifica quem a vive e a vivencia. Tal modificação afeta e modifica as próximas experiências, pois a vivência subsequente será experienciada por um indivíduo um pouco diferente daquele que a realizou, isto é, a pessoa que vai vivê-la já não é a mesma, devido às transformações resultantes das conexões entre experiências anteriores adquiridas e uma nova vivência a ser experienciada, conforme Dewey (1938).
}

https://periodicos.unifap.br/index.php/letras

Macapá, v. 6, n. 2, 2ㅇs semestre, 2016. 


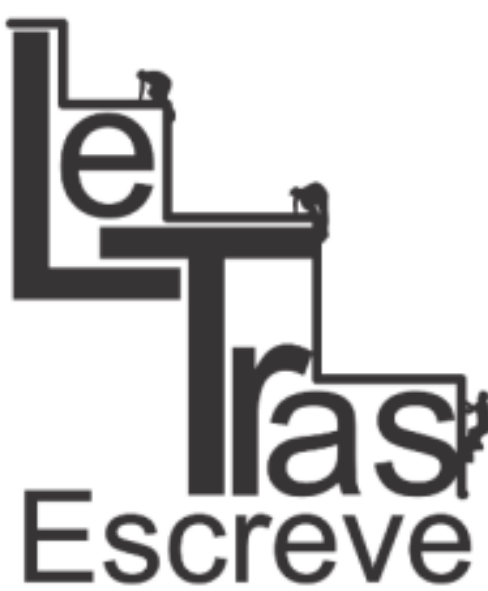

(ISSN 2238-8060)

representação.

Sob a previsão de identidade no circuito da cultura, porque entendo a sala de aula como um espaço de cultura, Hall (1997) afirma que somos diferentemente posicionados, em diferentes momentos e em diferentes lugares, conforme os papéis sociais que estamos exercendo. Essas posições assumidas, convergindo com Woodward (2009), são aquelas com as quais nos identificamos e, por isso, são constituidoras de nossa identidade. De fato, a complexidade da vida moderna, caracterizada principalmente pela intersecção da vida cotidiana com as relações econômicas, políticas, de hierarquia e de poder, parece exigir que assumamos diferentes identidades, as quais, por sua vez, podem, em certos momentos, estar em conflito.

Woodward (2009) observa que a identidade, além de simbólica, é cultural, tendo em vista que o que a constrói e mantém são os diferentes processos sociais e simbólicos em movimento. De acordo com a autora, "a cultura molda a identidade ao dar sentido à experiência e ao tornar possível optar, entre as várias identidades possíveis, por um modo específico de subjetividade" (p. 18-19). Para a autora, é importante observar a formação da identidade a nível local e pessoal, porque diferentes contextos sociais farão com que nos envolvamos em diferentes significados sociais. Assim, "somos posicionados e também posicionamos a nós mesmos de acordo com os campos sociais nos quais estamos atuando" (2009, p. 30 , grifo no original).

Segundo Hall (2009, p. 110), "as identidades são construídas por meio da diferença e não fora dela; por meio da relação com o outro, da relação com aquilo que não é, com precisamente aquilo que falta, o seu interior constitutivo". Nesse caso, as identidades, além de fluidas, fragmentadas, fraturadas e sociais, são o resultado de uma bem-sucedida articulação ou fixação do sujeito ao fluxo do discurso (HALL, 1990). Elas adquirem sentido por meio da linguagem - são construídas dentro e não fora do discurso -, e dos sistemas simbólicos pelos quais elas são representadas (WOODWARD, 2009).

https://periodicos.unifap.br/index.php/letras Macapá, v. 6, n. 2, 2o semestre, 2016. 


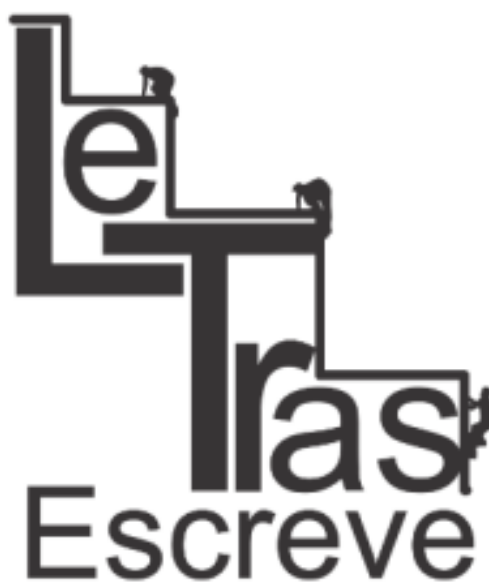

(ISSN 2238-8060)

Além disso, as identidades são relacionais (HALL, 1997), isto é, elas dependem de outras identidades para existir e, por conseguinte, marcar a diferença. São, de acordo com Silva (2009), pontos de apego temporário às posições (de poder) de sujeito que os discursos constroem para nós, obrigando-nos a assumi-las, a partir de práticas sociais que entrecruzam ou alinham-se. De acordo com o autor, o sujeito fala sempre, a partir de uma posição histórica e cultural específica. Em virtude disso, é necessária atenção à sua localização social e histórica (HALL, 1990).

Com base nos estudos interdisciplinares em conexão com a Linguística Aplicada, entendo que a identidade é um processo dinâmico construído por vários elementos: linguagem/discurso, crenças/representações, experiências, emoções etc. Por essa razão, torna-se oportuno ao professor de línguas saber mediar as negociações de sentido da vida em sala de aula refletindo sobre todos esses elementos que, imbricados, podem construir, desconstruir e reconstruir identidades, crenças e representações nos alunos as mais variadas possíveis.

\section{Ensino/aprendizagem crítico de língua}

Em termos de abordagem de ensino e formação docente, Smyth $(1991$, p. 122) foi um dos primeiros a sistematizar e propor a reflexão crítica: "descrever" (Quais as minhas práticas), "informar" (Que teorias exprimem as minhas práticas), "confrontar" (Quais são as causas?), e "reconstruir" (Eu deveria mudar?). Para ele, a reflexão crítica é estabelecida pelo envolvimento pessoal, investigativo e questionador da prática, como forma de repensar a ação, mantendo ou mudando-a. E esses tipos de ação apontados são estabelecidos de modo a confrontar teoria e prática, convertendo-se em possibilidades de emancipação.

Smyth (1992) afirma que é necessária a reflexão crítica das experiências a partir das formas de ensinar do professor, bem como uma análise sobre as intuições ou fatos que o levaram a assumir tais 


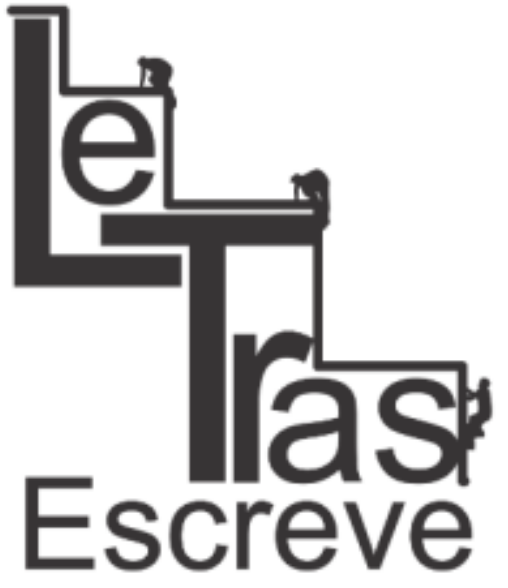

(ISSN 2238-8060)

práticas. Como os pensamentos pedagógico-críticos das décadas de 70 e 80 consideravam todo indivíduo como ser social, histórico e cultural (GIROUX, 1999), nesse sentido pregavam a importância da transformação e ressignificação da prática educacional, de modo a causar a emancipação. Isso porque, ao refletir criticamente, o professor em formação, no caso, poderia expressar e relacionar seu pensar e agir de acordo com as situações históricas discutidas/vividas, e isso o auxiliaria na conscientização de que os fatores que circundam o processo educacional não são neutros e, por isso, revelam interesses humanos, políticos, sociais e culturais, entre outros. Se isso ocorre, precisamos, então, começar a pensar em como trabalhar criticamente com a linguagem.

\section{Trabalho social com a linguagem como parte da mediação no ensino}

Bakhtin (1992) afirma que a linguagem consiste em um fenômeno intensamente social, histórico e ideológico no/pelo qual o sujeito se constitui, a partir de relações discursivas instauradas pela dialogia entre o eu e o(s) outro(s). Trazendo esse conceito para a sala de aula de línguas estrangeiras, é possível observar que, nesse espaço social, há, durante todo o tempo, negociação de significados, a qual atinge movimentos complexos e importantes de serem refletidos durante a formação de professores que ensinam línguas (JOHNSON, 2009).

Cabe destacar que a relevância do discurso só pôde ser orientada a partir da ampliação dos conceitos inerentes à língua, que, por sua vez, deixou de ser vista apenas como mero instrumento de comunicação, passando a assumir uma acepção mais abundante. Então, nessa visão mais contemporânea, a linguagem passa a ser concebida como forma de interação e como elemento constitutivo do conhecimento humano produzido socialmente (VYGOTSKY, 1998). O homem fala do mundo por meio da língua que, por sua vez, é tida como expressão de seu pensamento e de sua cultura, e acrescen-

https://periodicos.unifap.br/index.php/letras Macapá, v. 6, n. 2, 2ㅇ semestre, 2016. 


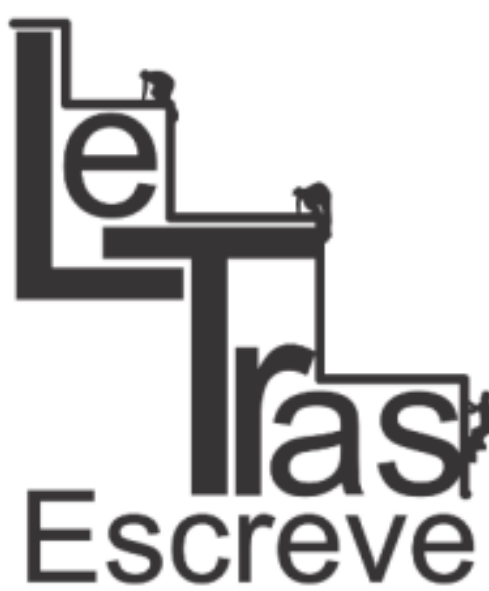

(ISSN 2238-8060)
tando-Ihe um viés discursivo, refere-se a um instrumento de comunicação imbuído de ideologias, intenções, entre outros elementos.

Diante desse conjunto, torna-se essencial observar a língua de um aluno acoplada de forma tênue à sua cultura, pensamento, discurso. Ao mesmo tempo, concebe-se que é por meio dessas mesmas dimensões que a figura social e política do professor atua, uma vez que, em sala de aula, esse agente reverbera discursos durante suas exposições de ensino, na mesma proporção em que os alunos o fazem diante da aprendizagem. Muitas vezes, é claro, isso ocorre sem que alunos e professor tenham plena consciência dessas práticas discursivas que envolvem elementos complexos, tais como a constituição de identidades e crenças.

O discurso permeia a constituição e a construção do homem por meio de processos dialógicos, de um ser que se relaciona com o outro (BAKHTIN, 1992). Nessa perspectiva, passa a ser compreendido além de sua natureza simbólica e representativa de mundo, e atinge sua natureza sócio-construcionista e constitutiva, de maneira a configurar-se, sobretudo, como o lugar privilegiado de manifestação de ideologias, entre outros valores sociais, conforme sugere Moita Lopes (2003). Talvez, por essa razão, o autor em questão afirma que a educação linguística esteja no centro da vida contemporânea, uma vez que o discurso ocupa um papel preponderante na vida social e, ecoando Santos (2000, p. 74), porque o homem vive em "um mundo no qual nada se faz sem discurso". Daí a importância de o professor de línguas preocupar-se com questões relativas à natureza sociopolítica dos processos de ensino-aprendizagem de línguas, tendo em vista que a situcionalidade da educação linguística concentra-se no mundo social e, dessa forma, há dois caminhos a serem percorridos por professores de LE:

ou colaboram com sua própria marginalização ao se entenderem como 'professores de línguas' sem nenhuma conexão com questões políticas e sociais [...], ou percebem que, tendo em vista o fato de trabalharem com linguagem, estão centralmente envolvidos com a vida política e social. (MOITA LO- 
PES, 2003, p. 33)

Como é possível observar, podem ser inúmeras as contribuições provenientes de professores de LE por meio da centralidade do discurso. Como estudiosos da língua, esses docentes possuem uma ferramenta com força potencial para construir, desconstruir e/ou reconstruir o mundo social, as pessoas e a si próprios, bastando apenas a ação por intermédio desse instrumento de comunicação. Aliás, convém acrescentar, é por meio da reflexão sobre o discurso que compreendemos onde estão situadas nossas ações pedagógicas, onde estão depositadas nossas crenças, de onde nos posicionamos e/ou situamos para falar, para agir de determinada forma. Mais ainda, apreendemos significados de construção da aprendizagem em sala de aula ao observar como esses discursos são construídos em/sobre a língua que se aprende, enfim, crescemos em vida e em língua e, de fato, nos formamos.

\section{Metodologia}

Esta é uma pesquisa qualitativa interpretativista. De acordo com Moita Lopes (1994), o paradigma interpretativista de pesquisa em Linguística Aplicada considera que o social é fruto de significados e interpretações que são produzidas pelos participantes de um determinado contexto. Nessa perspectiva, é o próprio sujeito humano que torna possível o conhecimento da realidade da forma como ele se dá nas diferentes instâncias e culturas em nossas sociedades. Não haveria, assim, realidades existentes em si mesmas sem o oIhar, o entendimento e a concepção social humana a seu respeito; também não haveria uma forma única ou objetiva de conhecer que fosse a resposta das indagações das pesquisas, pois são as interpretações dos pesquisadores e dos participantes que constroem as teorias que nomeiam e trazem à existência as teorias formadas a partir do que é investigado.

Para as interpretações e análises que aqui proponho, foram 
selecionados dados de pesquisas realizadas por mim na região centro-oeste do Brasil (OLIVEIRA, 2013). Os dados foram coletados dentro de uma perspectiva metodológica que atendia a investigação com foco em situações de ensino, de aprendizagem e de formação docente. Para este artigo, trato esses textos como narrativas (CLANDININ; CONNNELY, 2011), buscando contextualizá-los e tendo como foco questões de crenças e identidades dos atores do processo.

\section{Interpretação dos dados}

Os relatos e narrativas, com base nas experiências concretas e vicárias dos professores em formação, desenvolvidas ao longo dos estágios supervisionados obrigatórios, explicitaram crenças sobre a profissão docente. Apesar de considerá-los completamente imbricados, neste texto, os indícios de crenças se desdobram em sete classificações, as quais serão vistas detalhadamente:

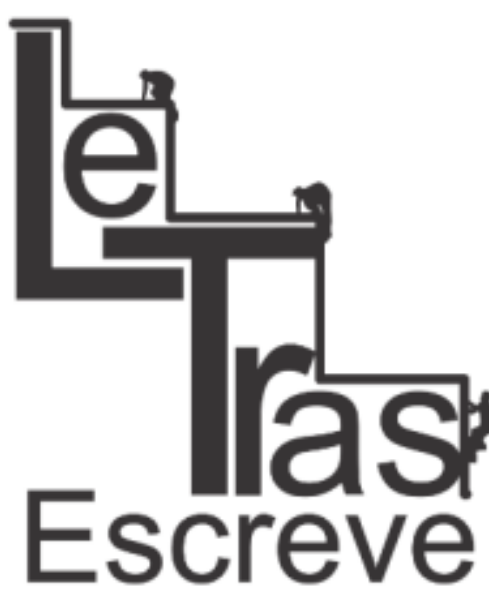

(ISSN 2238-8060)

Indícios de crenças relacionados à profissão docente

1. Os professores da escola não se esforçam para ensinar, estão acomodados.

2. Os alunos estão incivilizados.

3. As famílias não têm cumprido seu papel na educação dos seus filhos.

4. O sistema educacional, com suas leis escolares, exige muito dos professores e privilegia exclusivamente os alunos.

5. As condições da escola pública não são boas, e o governo atual não tem disponibilizado recursos.

6. As evoluções tecnológicas no mundo globalizado pressupõem mudanças no trabalho docente contemporâneo.

7. O trabalho docente é burocrático demais e extrapola o horário letivo.

1) Os professores não se esforçam para ensinar, estão acomodados

Foram recorrentes os relatos dos participantes acerca do comodismo docente que viram na escola-campo de estágio elou experienciaram ao longo de suas vidas em espaços escolares. Neste estudo, de modo crítico, Clara e Saracura manifestaram que existem professores despreocupados com a qualidade do ensino e que muitos estão apenas cumprindo rotineiramente a sua função administra-

https://periodicos.unifap.br/index.php/letras

Macapá, v. 6, n. 2, 2o semestre, 2016. 
tiva de comparecer à escola e preencher seu horário.

[01] Tem algum problema ali [em sala de aula], e eu acho que ninguém está preocupado com o problema que está ali, todo mundo se preocupa só em dar aula, pronto, e vamos passar de ano, e acabou, enfim, depois fica todo mundo falando que os alunos não aprendem, que não sei o quê, mas também ninguém se esforça [...] já que o governo paga pouco então para que eles vão se esforçar para fazer alguma coisa, né? Eles vão bater o ponto deles, ganhar o salário deles, mais na manha, sabe? Ninguém está preocupado se o aluno está aprendendo de verdade, eu acho que não está mesmo! (Clara)

[02] Parecia que [os professores da escola] estavam ali só por estar. Entendeu? E a gente trabaIhando no estágio, a gente via alguns professores assim, então, não tem muita expectativa. (Saracura)

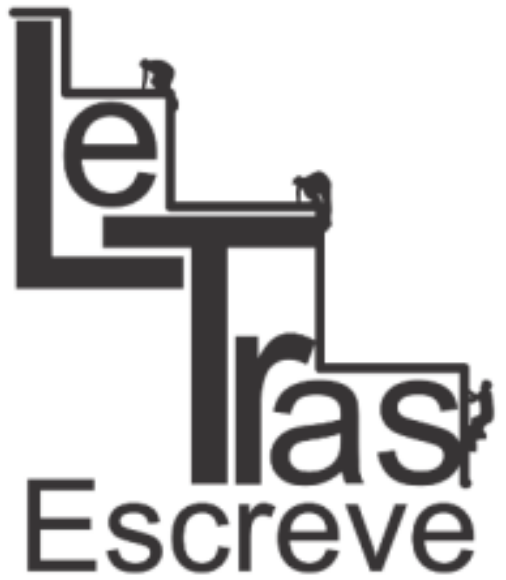

(ISSN 2238-8060)

Hargreaves (1998) relata que é comum haver professores que realizam seu trabalho de maneira honesta e profissional, ao passo que também existem professores que não se comprometem e refugiam-se no anonimato e no isolamento característico da profissão para desenvolverem um ensino que priva o direito de aprender dos alunos. Parece claro que, em alguns casos, o tempo de serviço é um fator negativo, visto que o professor que não se atualiza, não o faz porque não está motivado com a profissão, porque não tem condições - tempo e dinheiro, e, com isso, sua abordagem torna-se rotineira e sem reflexão. Partindo desse pressuposto, podemos combinar a harmonia deste indício com outros que serão tratados a seguir.

Apesar de sabermos que o professor não consegue superar todas as adversidades do sistema, ele precisa primar por manter seu compromisso moral e zelar por seu trabalho independentemente de qualquer aspecto. Para isso, ele precisa propiciar a seus alunos momentos em que possam problematizar as viabilidades e as inviabilidades da profissão à medida que realiza seu trabalho em sala de aula. Não obstante, a minha preocupação reside no fato de apenas serem produzidas práticas e discursos docentes que constantemente estigmatizam a profissão em sala de aula, seja nos comentários 


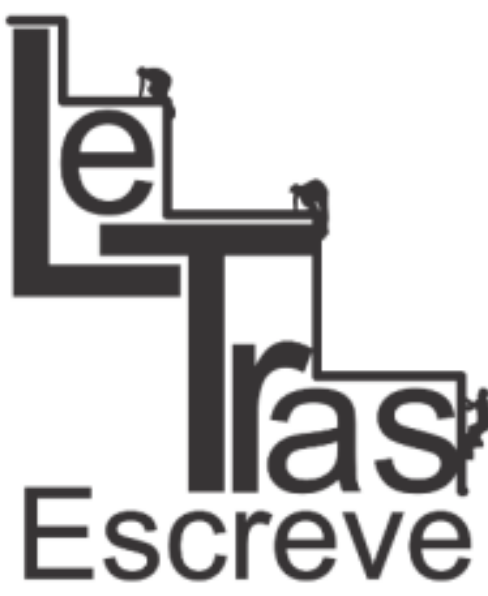

(ISSN 2238-8060)

com os alunos ou no reforço de outros vários discursos que permeiam a escola e o trabalho do professor.

Como a profissão é caracterizada por sua interatividade e relação social, a meu ver, o dizer e o fazer em sala de aula acerca da profissão, se positivos e com propósitos muito bem definidos, podem (re)acender, mesmo que de forma indireta e inconsciente, 0 modo como os alunos da escola, no futuro, conceberão a profissão docente. As atuações e performatividades docentes positivas em relação ao ofício pode fazer que aqueles alunos da escola avaliem de forma diferente a imagem da docência. O discurso e prática docente talvez sejam um dos instrumentos primordiais na compreensão daquilo que os alunos e a sociedade possuem acerca dessa profissão. Se, nos dias atuais, ela não tem se mostrado como uma profissão digna, nobre e legítima, é urgente repensarmos que tipo de identidades profissionais estamos (re)produzindo a partir de nossas experiências de ensino, configurando, por consequência, uma resposta de posicionamento dos nossos alunos diante do fato.

\section{2) Os alunos estão indisciplinados}

Levando-se em conta que as emoções dos professores influenciam o que eles pensam sobre os alunos, busquei descobrir como os participantes perceberam os discentes. Todos os participantes fizeram menção, ao longo das narrativas e relatos, da onda de indisciplina por parte dos alunos. As experiências obtidas especialmente em salas de aula do estágio, ao longo das vivências profissionais, colaboraram para a construção de tais cognições docentes. O mais curioso sobre esse fato é a frequente comparação que cada participante faz com sua época escolar. Na opinião de Assaré e Juliana, antigamente havia mais respeito e consideração pelo professor. A profissão era tida como nobre e honrosa e representava autoridade. Hoje isso não existe mais, conforme é mencionado nos seguintes relatos:

https://periodicos.unifap.br/index.php/letras

Macapá, v. 6, n. 2, 20 semestre, 2016. 


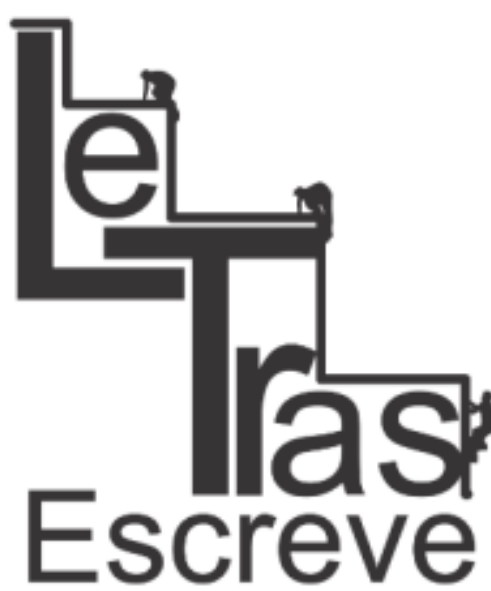

(ISSN 2238-8060)
[03] Hoje o aluno não respeita essa hierarquia, né? Ele trata o professor como ele trata o colega, quando respeita a esse ponto, porque tem aluno que não respeita nem a esse ponto. [...] inclusive, eu tinha medo de alguns professores [...] e eu lembro que a quarta série eu tinha pavor, porque eles falavam muito que a professora da quarta série era muito brava. (Assaré)

[04] Na época da escola, minha mãe me falava assim: "Olha, você não desobedeça ao professor, porque se você desobedecer, quando chegar em casa, você vai apanhar, porque o professor é seu segundo pai, sua segunda mãe. Então, a gente já saía lá de casa com o pensamento seguinte: que o professor era algo muito grande. Nossa! Eu admirava todos os professores, nunca respondia, e tinha um carinho muito grande por todos eles. Por mais assim que eu achasse: "Ah, esse professor não vai com a minha cara!", nunca na minha vida eu desrespeitei nenhum professor, e a gente via o professor assim como um rei. (Juliana)

Para Charlot (2002), o acúmulo de incivilidades, ilustradas em pequenas grosserias, piadas de mau gosto, recusa ao trabalho proposto pelo professor, indiferença ostensiva para com o ensino, pode gerar um clima em que o professor e os alunos sintam-se profundamente atingidos em suas identidades pessoais e profissionais. Em relação ao professor, o perfil heterogêneo do alunado atingido por novas e complexas configurações dos dinamismos sociais presentes nos modos de vida atual, que também demandaria uma formação consistente na graduação pautada na reflexão, também não faz parte dos modelos construídos nesses espaços. Geralmente os docentes em formação inicial não estão preparados para lidar com os inúmeros problemas espontâneos ocorridos em situação real de sala de aula, porque pouco se pensou nessa direção.

Em face disso, é imperativa a sensibilidade de formadores em trabalhar, com seus professores em formação, o aprimoramento das relações sociais de sala de aula, de forma a ressignificar determinadas experiências e interações. Até mesmo porque tais processos entrelaçam a vida diária de sala de aula e acabam por contornar profissionalmente a docência e por afetar diretamente a constituição 


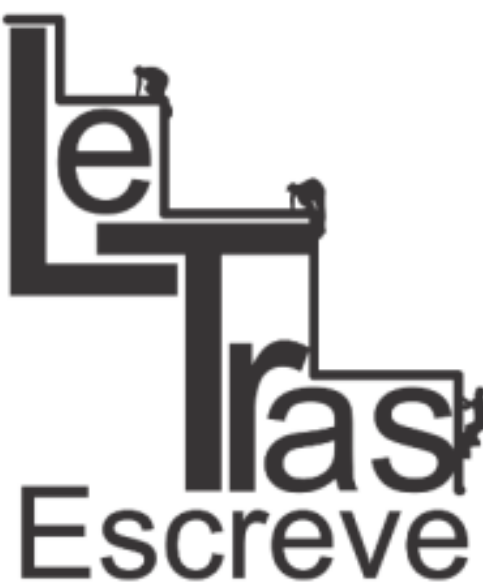

(ISSN 2238-8060)

do "ser professor" no candidato à docência.

Do ponto de vista discente, o caminho torna-se inverso, ainda se pensarmos que, na condição de alunos, os sujeitos também se constituem e constroem identidades a partir da vivência social que estabelece com os outros. Então, se o estudante não possui boas referências afetivas e culturais internalizadas pela convivência cotidiana positiva em espaços de sala de aula com seus professores, possivelmente crenças configurarão possibilidades de exercer ou não, no futuro, a profissão que ele está a todo tempo a observar em sala de aula.

É interessante observar, de certa forma, as impressões que os participantes deste estudo possuem em relação ao aluno, pois, conforme avalia Marcelo (2009), os discentes desempenham um papel relevante na configuração das identidades profissionais docentes, uma vez que eles estão a conceder certo tipo de resposta à atuação do professor em todo momento. Na concepção dos participantes, os alunos são um misto de complexidade e heterogeneidade, o que auxilia ainda mais essa representação que têm do caos em sala de aula. Contudo, é relevante refletirmos até que ponto é legítima a moda de atribuir o insucesso da aprendizagem somente ao aluno ou às questões sistemáticas, uma vez que a prática docente, numa perspectiva relacional, abrange uma complexidade de elementos que, em interação e negociação de sentidos, farão substancial diferença - positiva ou negativa - ao próprio professor.

3) As famílias não têm cumprido seu papel na educação dos seus filhos

Os participantes foram unânimes em considerar que a família designa a educação do filho exclusivamente ao professor. Janaina e Juliana, por exemplo, avaliam que, na concepção dos pais, a escola, mais especificamente representada pela figura do professor, deve dar conta de toda a educação.

https://periodicos.unifap.br/index.php/letras

Macapá, v. 6, n. 2, 2o semestre, 2016. 


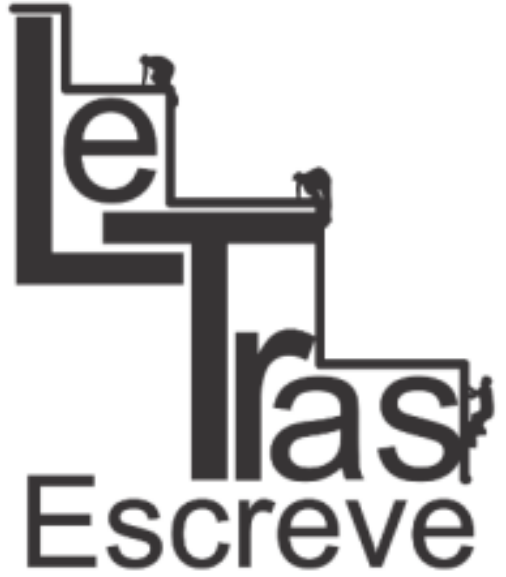

(ISSN 2238-8060)
[05] Ah, eu acho que o problema maior é o pai colocar o aluno na escola e achar que a escola tem que fazer tudo: tem que educar e que a criança não tem que trazer educação nenhuma de casa. (Janaina)

[06] Hoje os jovens saem de casa para a escola e, na concepção da família, a escola vai educar seu fiIho, e não é verdade: a escola ensina, prepara, mas a educação tem que vir de casa. (Juliana)

Da mesma forma, parece consensual a importância do papel da família em conjunto com os professores na educação dos filhos/alunos. John Kenedy, por exemplo, alega que a escola não possui a presença dos pais e que, em situações de conselho de classe, boa parcela não aparece para conversar com os professores a respeito dos filhos. Em virtude dessas crenças, Chica da Silva e Soares refletem que muitos dos problemas que o professor enfrenta, hoje, poderiam ser reduzidos caso a família participasse mais diretamente da educação dos filhos e dialogasse mais com o professor:

[07] Na minha concepção o quadro caótico em que se encontra a Educação regular é uma questão cultural, reflexo da educação recebida em casa ou falta dela. Vejo que a educação da rede pública e/ou particular é um contínuo da educação trabalhada na primeira instituição - a família. Penso que, para que a educação escolar consiga contribuir para a educação secular dos alunos, é preciso, antes de tudo, educar os pais na criação de seus filhos. Sei que isso não é função da escola, mas vimos que muitos de nossos jovens não têm estrutura familiar moldada na moral, na ética, no bom caráter e principalmente no respeito com os demais e até consigo mesmos. (Chica da Silva)

[08] Eu acho que a base de tudo é a família, e hoje os alunos querem muito direito e poucos deveres [...] Então, se os pais estiverem caminhando junto com eles na escola, é possível conciliar as duas coisas: os direitos e os deveres [...] Ser professor é estar interagindo tanto com os alunos, quanto com os pais, quanto com os professores, é um conjunto. (Soares)

Sobre tais fatores, Marchesi (2008) adianta que as crenças que os professores têm a respeito das relações interpessoais no

https://periodicos.unifap.br/index.php/letras

Macapá, v. 6, n. 2, 2o semestre, 2016. 
ensino provocam neles alguns tipos de respostas emocionais. Marcelo (2009) aponta, ainda, que o fato de as famílias estarem cada vez mais heterogêneas, deixando de lado sua parceria com a escola, afeta claramente as identidades profissionais docentes, justamente por não ter o trabalho profissional amparado pela parte familiar. No caso deste estudo, é possível deduzir que a ausência da família outorga mais responsabilidade ao professor que, por sua vez, sente a necessidade de redesenhar o seu papel e compromisso com certos valores trazidos pelos alunos para a sala de aula. Assim, é normal que ele busque cumprir a sua função docente e assuma outras atribuições que deveriam ser destinadas à família. Contudo, observamos que, segundo Clara, o problema da educação atual parece não ser apenas da família:

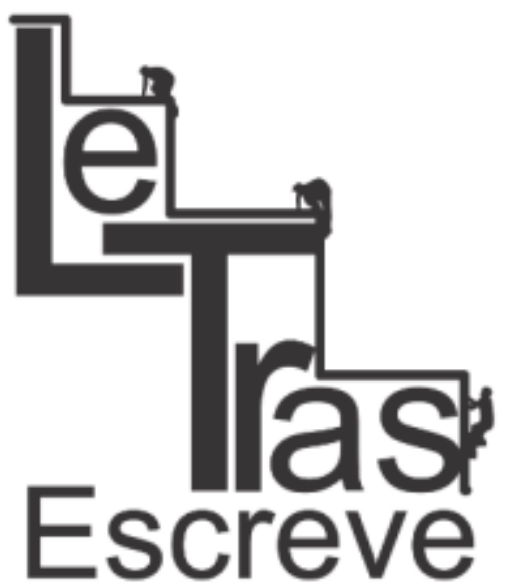

(ISSN 2238-8060)
[09] Eu acho que cada um tem um pouquinho de culpa. O governo tem sua parcela de culpa porque não investe em educação, não investe nos professores, não investe em qualificação. O professor tem a sua culpa porque acomoda, não faz nada para fazer diferente também, porque é só um e não vai conseguir fazer nada. [...] A culpa está no aluno também, porque hoje em dia mudou muito. Lembrome de quando eu fazia ensino fundamental, médio, gente! Não existia o que existe em sala de aula hoje! (Clara)

Clara discute com outros participantes acerca da grande problemática atual da educação e o papel da família. Para ela, a culpa pelos maus resultados hoje não envolve apenas uma questão ou um agente, a culpa é dimanada de uma série de tensões produzidas por vários fatores, entre eles, o absentismo familiar na escola, que, por sua vez, se soma a outros aspectos cujas acusações passam a ser distribuídas a vários atores sociais do processo: professor, alunos e terceiros. Esses resultados nos convidam a pensar em várias conjunturas e processos pedagógicos, já que a tendência natural de muitos docentes, talvez como solução imediata para o problema, parece ser a própria isenção da responsabilidade pela problemática da qualidade de ensino.

https://periodicos.unifap.br/index.php/letras

Macapá, v. 6, n. 2, 2ㅇ semestre, 2016. 


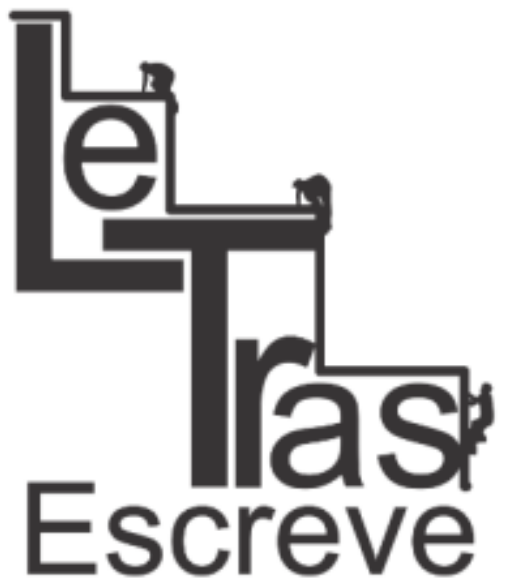

(ISSN 2238-8060)
4) O sistema educacional, com suas leis escolares, exige muito dos professores e privilegia exclusivamente os alunos

Entre outros participantes, Assaré, no excerto 01, informou que, hoje, tem ocorrido uma reviravolta no sistema educacional em relação a leis educacionais e regimentos institucionais que, de certo modo, concedem muitos benefícios aos alunos e muitos deveres aos professores. Tais exigências, vindas de uma hierarquia maior, acabam por privilegiar e garantir direitos ao aluno e, na concepção das participantes, ao mesmo tempo rompem com o paradigma de respeito que, até décadas anteriores, o professor possuía. Além disso, as exigências profissionais descrevem um cotidiano no qual a atuação docente não se resume apenas ao campo da didática, todavia engloba um espectro mais abrangente, envolvendo, entre outras obrigatoriedades, o enfrentamento de questões relativas à convivência e ao comportamento, bem como à formação ética de valores e atitudes, as quais se conectam aos indícios de crenças 2 e 3, mencionados anteriormente (cf. Quadro 1).

Embora possamos entender que a tendência autoritária docente também não colabore para um processo de mediação de aprendizagem efetivo durante as relações de sala de aula, do ponto de vista sistemático, muitas dessas crenças sufocam o trabalho docente, pois, de acordo com Juliana, o professor fica de "mãos atadas diante dos benefícios discentes", e ecoando os pensamentos de Chica da Silva, "o professor é obrigado a passar quem não sabe". Vejamos o depoimento de Assaré:

[10] Hoje, com essa história que não se pode reprovar, os alunos tiram nota ruim e o professor tem que fazer qualquer coisa para eles melhorarem essa nota. Na nossa época, não tinha isso: você passava ou não passava. E você tinha que respeitar o professor e tinha que estudar. Hoje, não! O aluno não estuda, o professor tem que aprová-lo de todo jeito, vai empurrado, né? Não respeita. [...] a falta de respeito, a falta de interesse são coisas que vão desa- 
nimando, a própria instituição, a escola mesmo, você não tem base de apoio, muitas coisas vão te desmotivando, vão te desanimando. (Assaré)

Como explica Imbernón (2006), o desenvolvimento profissional docente não consiste apenas no desenvolvimento pedagógico, no conhecimento e compreensão de si mesmo, no desenvolvimento cognitivo ou teórico, mas tudo isso ao mesmo tempo delimitado ou incrementado por uma situação profissional que permite ou impede o desenvolvimento de uma carreira docente. Como temos visto, o sistema educacional, burocrático, constantemente impõe modelos intervencionistas e formalizados, acabando por obstaculizar a autonomia e os processos colaborativos de formação. Mais ainda, dificultam o trabalho do professor que, por sua vez, se sente ameaçado em caso de não cumprimento da ordem. Na maioria dos participantes deste estudo, a incumbência docente do papel de herói, isto é, o de garantir a aprendizagem dos alunos acima de qualquer problema, com certeza, pode incidir diretamente na identificação e na construção das identidades profissionais. Infelizmente, o significado que se tem dessa configuração são emoções negativas que engrossam a não identificação com a profissão. Ao contrário do que deveria ocorrer em relação a esse fato, a profissão docente deveria comportar o conhecimento pedagógico específico pautado na ética, na moral e na necessidade de dividir responsabilidades com outros agentes sociais, visto que o professor precisa de amparos sociais (colaboração entre pares, confiança etc.), para que suas identidades profissionais se confirmem.

5) As condições da escola pública não são boas, e o governo atual não tem disponibilizado recursos

Os participantes acreditam que as condições oferecidas pela escola pública para o professor exercer o seu trabalho são muito precárias. Com exceção de Flor, que sempre busca observá-las por um lado positivo, é possível perceber a presença de valores ne- 
gativos destinados à qualidade da educação e da escola pública nas declarações de outros participantes. Entre os argumentos mais comuns, está a falta de investimento do governo em recursos materiais e humanos, caracterizada a) pelo despreparo docente, b) pela má estrutura física do prédio e das salas de aula, c) pela inexistência de recursos e equipamentos importantes para o ensino e d) pela superlotação de alunos em salas, como ilustrado nos exemplos a seguir:

[11] Está muito deficitário, com problemas como: falta de professores concursados, mal preparo dos mesmos, falta de incentivo do governo, má qualidade dos livros oferecidos, decadência de seus prédios, falta de recursos financeiros e profissionais. $O$ ensino público está vivendo um mau momento, de extrema decadência e desvalorização por todos os lados. (Clara)

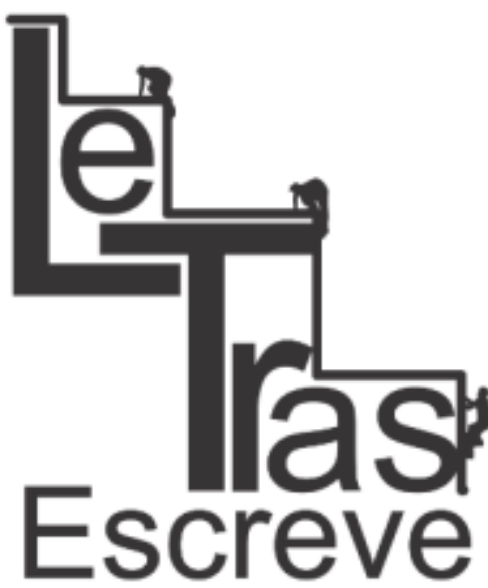

(ISSN 2238-8060)

[12] O principal desafio [...] é lidar com salas cheias de alunos, lugar em que, às vezes, não há $1 \mathrm{~m}^{2}$ livre para que professores e alunos se movimentem na sala. (John Kenedy)

Não se pode desprezar o fato de que, na condição de alunos, os participantes possam ter associado, à constatação da própria experiência de ensinar, a experiência de aprender, uma vez que a maioria deles estudou em escola pública. Por essa razão, estabeleço que, correlacionadas à teoria da observação da aprendizagem de Lortie (2002), os participantes possam ter incluído, em alguns momentos da análise apresentada, certas cognições e emoções no modo como percebem e endereçam valores ao sistema público de ensino, significados esses oriundos de sua época.

6) As evoluções tecnológicas no mundo globalizado pressupõem mudanças no trabalho docente contemporâneo

Boa parcela dos participantes incrementa suas narrativas com base em todo o trabalho que o professor deveria desenvolver frente ao desafio ocorrido na educação contemporânea. Frequentemente, os depoimentos convergem para a dificuldade que o profes- 
sor enfrenta perante as mais variadas ordens de adaptação às transformações ocorridas na sociedade da informação, em que, a cada dia, mais tecnologias são inseridas em nosso meio social. No geral, tais demandas impõem uma necessidade de ruptura docente com paradigmas de sua abordagem de ensino e dos modos convencionais de atuação e, não raro, configuram-se como um desafio a ser enfrentado por aqueles que se ingressam na profissão. Juliana, por exemplo, menciona a questão das novas tecnologias:

[13] Os professores de antes não tinham que competir com as mídias oferecidas hoje, quase que praticamente de graça. Então fica difícil "educar", são muitas coisas envolvidas. (Juliana)

O pensamento de Juliana e de alguns de seus colegas

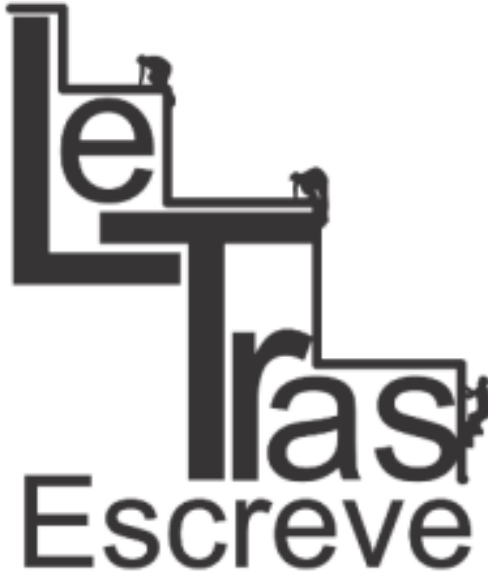

(ISSN 2238-8060)

também ilustra muito bem o famoso dilema que atinge as discussões em programas de formação docente: os professores parecem compreender que as tecnologias de informação e de comunicação que os alunos trazem para a sala de aula, ou, ainda, a que eles fazem menção nesses espaços, pressupondo um uso generalizado em ambientes extraclasse, em vez de serem concebidas como recurso metodológico na prática docente, geralmente são vistas com reservas e, em alguns casos, com certa resistência pelos docentes, talvez pelo tímido conhecimento da ferramenta, de sua manipulação ou até mesmo de seu efeito na aprendizagem (OLIVEIRA, 2013). No entanto, é importante resgatar que, ao contrário do que se possa imaginar, a utilização de recursos tecnológicos em sala de aula deveria estar incluída na agenda do professor que, por sua vez, deveria estar mais bem preparado para percebê-las, conhecê-las e, a partir disso, desenvolver um trabalho com preparação e reflexão sobre o uso, a fim de que tais recursos funcionem como auxiliares da abordagem de ensino e, por conseguinte, facilitem o acesso discente ao conhecimento e, com isso, possa favorecer formas autônomas e conscientes de aprendizagem. 
7) O trabalho docente é burocrático demais e extrapola o horário letivo

Os participantes expressaram que a burocracia do trabaIho do professor e o fato de sua atividade exceder os espaços de sala de aula são as principais não identificações com a profissão docente. Para Roberto, o professor possui um excesso de tarefas extras sala: corrigir trabalhos, provas, elaborar aulas, fazer planos, pesquisar, preencher diários etc., afazeres esses não muito comuns em outras profissões.

[14] Acho que na profissão docente você tem coisa demais para fazer. Mais do que em outras profissões. Isso eu acho chato. O professor fica preocupado com tanta coisa antes de entrar e de sair da sala de aula. Preencher um monte de fichas, dados, fazer planos, isso, aquilo. Exagera demais, extrapola. (Roberto)

É possível reparar nas falas de Roberto e de Chica da Silva a disponibilidade de tempo que o professor deve possuir para as várias atividades que seu trabalho pressupõe. O professor geralmente estende seu período de trabalho para o âmbito familiar, fazendo de sua casa a extensão de seu local de trabalho.

\section{Considerações finais}

Descortinam-se algumas inquietações ao observarmos os sete indícios apresentados, inerentes ao que esses futuros professores pensam e sentem ao longo do processo de formação docente. De modo geral, podemos verificar que os participantes reproduzem, diante de todas as crenças mobilizadas, discursos comuns que permeiam a escola, a mídia, a sociedade. Não há nada de muito novo nos resultados apurados. Embora os participantes se certifiquem narrativamente da existência de tais discursos e práticas, ao longo do processo de formação, como professor formador, sinto que a sua

https://periodicos.unifap.br/index.php/letras

Macapá, v. 6, n. 2, 2ㅇ semestre, 2016. 


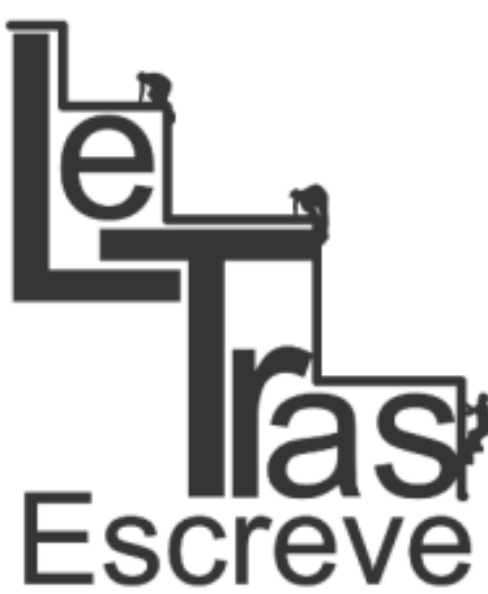

(ISSN 2238-8060)

problematização ainda se mostra inconsistente ou quase inexistente nesses espaços.

Do contrário, seria conveniente, em ambientes de formação inicial, dialogar com os futuros professores acerca da realidade existente em sala de aula, dos ideais que envolvem a profissão e a formação docente, sobre o que se pode fazer diante das condições reais em que os professores ensinam e trabalham e, obviamente, com isso, reduzir as nuanças tecnicistas do processo formativo. Ora, se entendemos que cientificamente discursos são importantes mediadores na transmissão da cultura sistematizada, logo deveríamos problematizá-los. Sem esse processo reflexivo docente na licenciatura, o pensamento docente pode ficar à mercê de entraves que poderiam ter sido sanados com uma construção positiva ou questionadora dos processos sociais e culturais da docência e do ensino.

Não podemos negar que são muitos os desafios com que os futuros professores deste estudo precisam lidar. O amálgama das crenças por eles apresentadas acaba pesando na construção de suas identidades profissionais, uma vez que tais elementos esbarram diretamente no modo como percebem a docência e, automaticamente, a partir dessa percepção, agem e significam o seu trabaIho, de modo a produzir identidades em seus interlocutores alunos. Trata-se de um trabalho complexo por parte do docente. Entretanto, não podemos delegar exclusivamente ao profissional a tarefa de prover condições propícias para o ensino e aprendizagem dos alunos, uma vez que o profissional não é o único responsável por acionar a aprendizagem por intermédio de seu trabalho.

\section{Referências}

BAKHTIN, M. Marxismo e filosofia da linguagem. Tradução Michel Lahud e Yara Frateschi Vieira. São Paulo: HUCITEC, 1992.

BARCELOS, A. M. F. Metodologia de pesquisa das crenças sobre aprendizagem de línguas: estado da arte. Revista Brasileira de Lingüística Aplicada, v.1, n.1, p. 71-92, 2001. 


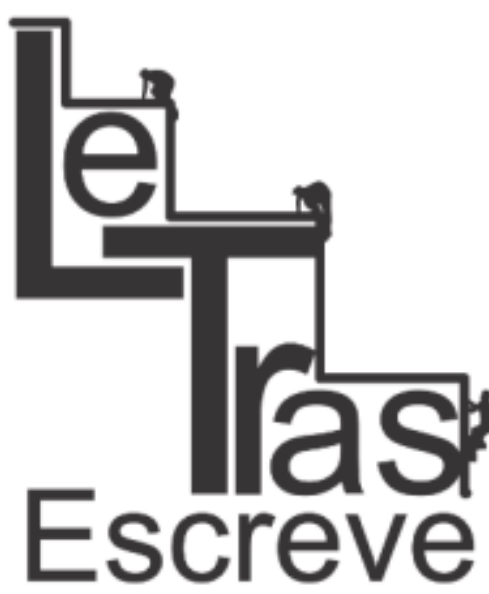

(ISSN 2238-8060)
BARCELOS, A. M. F. Crenças sobre aprendizagem de línguas, linguistica aplicada e ensino de línguas. Linguagem \& Ensino (UCPel), Pelotas - RS, v. 7, n.1, p. 123-156, 2004.

. Cognição de professores e alunos: tendências recentes na pesquisa de crenças sobre ensino e aprendizagem de línguas. In: BARCELOS, A. M. F.; ABRAHÃO, M. H. V. (Org.). Crenças e ensino de línguas: foco no professor, no aluno e na formação de professores. Campinas: Pontes, 2006. p. 15-41.

. Desvelando a relação entre crenças sobre ensino e aprendizagem de línguas, emoções e identidades. In: GERHARDT, A. F. M.; AMORIM, M. A.; CARVALHO, A. M. (Org.). Linguística Aplicada e ensino: língua e literatura. Campinas: Pontes, 2013. p. 153-186 CHARLOT, B. A violência na escola: como os sociólogos franceses abordam essa questão. Sociologias, Porto Alegre (UFRGS), n.4, p. 432-442, 2002.

CLANDININ, J. D.; CONNELLY, M. F. Pesquisa narrativa: experiência e história em pesquisa narrative. Tradução Grupo de Pesquisa Narrativa e Educação de Professores do ILEEL/UFU. Uberlândia: EDUFU, 2011.

DEWEY, J. Experience and education. New York: Touchstone, 1938.

GIROUX, H. A. Professores como intelectuais transformadores. In:

GIROUX, H. A. Os professores como intelectuais: rumo a uma pedagogia crítica da aprendizagem. Porto alegre: Artes Médicas, 1999. p. 157-164.

HALL, S. Cultural identity and diaspora. In: RUTHERFORD, J. (ed.). Identity: community, culture, difference. London: Lawrence \& Wishart, 1990.

. The work of representation. In: HALL, S. Representation: cultural representations and signifying practices. London: SAGE Publications, 1997. p. 13-74.

. Quem precisa da identidade? In: SILVA, T. T.;

WOODWARD, K. Identidade e diferença: a perspectiva dos estudos culturais. São Paulo: Vozes, 2009.

https://periodicos.unifap.br/index.php/letras Macapá, v. 6, n. 2, 2ㅇs semestre, 2016. 


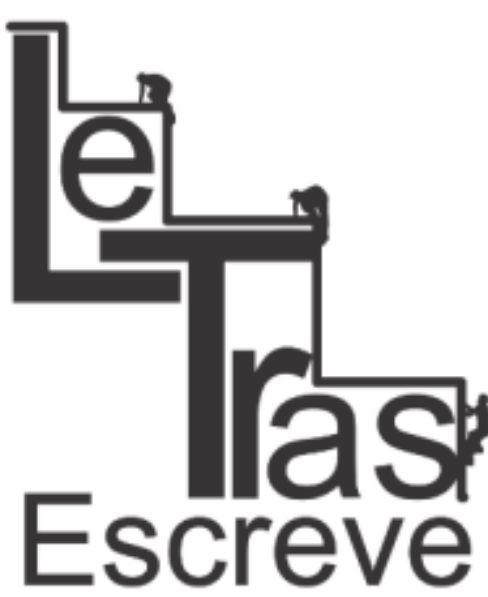

(ISSN 2238-8060)
HARGREAVES, A. The emotional practice of teaching. Teaching and Teacher Education, v. 14, n. 8, p. 835-854, 1998.

IMBERNÓN, F. Formação docente e profissional: formar-se para a mudança e a incerteza. São Paulo: Cortez, 2006.

JOHNSON, K. E. Second language teacher education: a sociocultural perspective. New York: Routledge, 2009.

LORTIE, D. C. Schoolteacher: a sociological study. Illinois: University of Chicago Press, 2002. 308 p.

MARCELO, C. Identidade docente: constantes e desafios. Formação docente: revista brasileira de pesquisa sobre formação de professores, vol. 1, n. 1, p. 109-131, 2009.

MARCHESI, A. O bem-estar dos professores: competências, emoções e valores. Porto Alegre: Artmed, 2008.

MICCOLI, L. S. A experiência na lingüística aplicada ao ensino de línguas estrangeiras: levantamento, conceituação, referências e implicações para a pesquisa. Revista Brasileira de Lingüística Aplicada, vol. 7, n. 1, p. 208-248, 2007.

MOITA LOPES, L. P. Pesquisa interpretativa em Linguística Aplicada: a linguagem como condição e solução. São Paulo: Delta, vol. 10, n. 2, 1994, p. 329-338.

MOITA LOPES, L. P. Socioconstrucionismo: discurso e identidades sociais. In: MOITA LOPES, L. P. (Org.). Discursos de identidades: discurso como espaço de construção de gênero, sexualidade, raça, idade e profissão na escola e na família. Campinas, SP: Mercado de Letras, 2003. p. 13-38.

OLIVEIRA, Hélvio Frank. Esculpindo a profissão professor: experiências, emoções e cognições na construção das identidades docentes de licenciandos em Letras. 302 f. Tese (Doutorado em Letras e Linguística) - Universidade Federal de Goiás, Goiânia, 2013.

SANTOS, Milton. Por uma outra globalização. Rio de Janeiro: Record, 2000.

SMYTH, J. Critical pedagogy of supervision. In: SMYTH, J. Teacher as collaborative learners: challenging dominant forms of supervision. Buckingham: Open University Press, 1991. p. 119-137.

https://periodicos.unifap.br/index.php/letras Macapá, v. 6, n. 2, 2o semestre, 2016. 
cational Research Journal. v. 29. 1992.

SILVA, T. T. A produção social da identidade e da diferença. In: SILVA, T. T.; HALL, S.; WOODWARD, K. (Org.). Identidade e diferença: a perspectiva dos estudos culturais. 9 ed. São Paulo: Vozes, 2009. p. 73-102.

WOODWARD, K. Identidade e diferença: uma introdução teórica e conceitual. In:

SILVA, T. T. da. (Org.). Identidade e diferença: a perspectiva dos estudos culturais.

Petrópolis: Vozes, 2009. p. 7-72.

VYGOTSKY, L. S. A formação social da mente: o desenvolvimento dos processos psicológicos superiores. São Paulo: Martins Fontes, 1998.

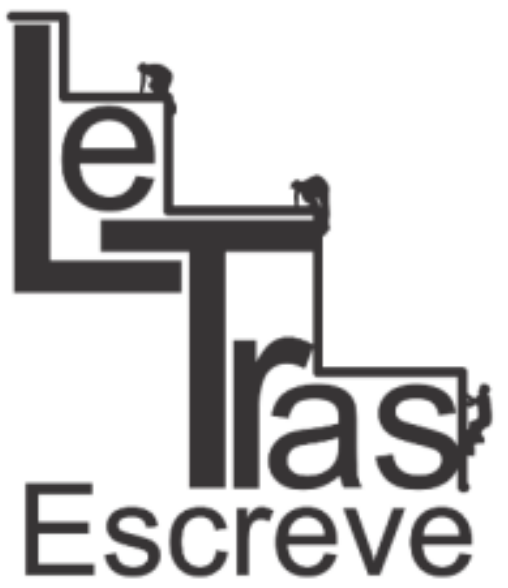

(ISSN 2238-8060)
Psicologia pedagógica. Tradução Paulo Bezerra. São

Paulo: Martins Fontes, 2001.

Recebido em: 20 de novembro de 2016

Aprovado em: 04 de janeiro de 2017 